\title{
A Challenging Diagnosis
}

\section{Carlos-Manuel Ortiz-Mendoza*}

Department of Surgery, School of Medicine, National Autonomous University of Mexico (UNAM), Mexico

William Osler wrote: "Variability is the laws of life and as no two faces are the same, so no two bodies are alike, and no two individuals react alike and behave alike under the abnormal conditions which we know as disease."

In this issue of Clinical Case Reports, Tanyildiz HG et al. [1] present a challenging diagnosis of cobalamin $(\mathrm{Cbl})$ deficiency mimicking acute leukemia in a child. This case is relevant since there are no previous reports in childhood.

Let's analyze the case: The patient was a male teenager with a threemonth history of dizziness, progressive fatigue, weight loss, and night sweats. Skin pallor was revealed on physical examination. However, an interesting habit was that he was a vegetarian. Adolescence is a period of fast growth with increased necessities of several nutrients.

His blood tests showed pancytopenia; however, the peripheral blood smear showed macrocytosis and neutrophil with hypersegmentation. Examination of bone marrow aspiration showed blastic differentiations that mimicked acute leukemia. Until here, evidence was consistent with diagnosis of leukemia.

Conversely, flow-cytometry and cytogenetic results were normal. It was in this point when the serum level of cobalamin, and homocysteine were crucial. The authors concluded: "clinicians must be alert about blastic differentiations that mimicked acute leukemia. In apparent child cases of leukemia, with normal flow-cytometry and cytogenetic results, it should be better to measure the serum level of $\mathrm{Cbl}$ and homocysteine."

Accordingly with this case, Cbl deficiency should be considered a differential diagnosis in children with suspected of acute leukemia; mainly, in those showing peripheral blood smears with macrocytosis and hypersegmented neutrophils. And only later, the serum level of $\mathrm{Cbl}$ and homocysteine should be measured before to bone marrow aspiration.

Remember that there are not "standard" patients; the disease is a dynamic event. It results of interactions between risk factors or behaviors in a susceptible individual. Illness is a continuum event, where the start is asymptomatic and just the advanced stages are clinically evident. Nevertheless, what are the reasons why only some patients are affected? These circumstances entail individual or innate characteristics. Thus, like our finger-prints, we are similar and different at the same time; the medical treatments must be individualized because there are not "standard" patients.

Enjoy this interesting case.

\section{Reference}

1. Tanyildiz HG, Malbora B, Yesil S, Tekgunduz SA, Candir MO, et al. (2014) Vitamin B12 Deficiency Mimicking Acute Leukemia in a Child. J Clin Case Rep 4: 430.

*Corresponding author: Carlos Manuel Ortiz Mendoza, Department of Surgery, School of Medicine, National Autonomous University of Mexico (UNAM), Mexico, Telephone: (0155)52652949; Email: cortizmendoza@yahoo.com.mx

Received December 31, 2014; Accepted January 02, 2015; Published January 04, 2015

Citation: Ortiz-Mendoza CM (2015) A Challenging Diagnosis. J Clin Case Rep 5: e141. doi:10.4172/2165-7920.1000e141

Copyright: (C) 2015 Ortiz-Mendoza CM. This is an open-access article distributed under the terms of the Creative Commons Attribution License, which permits unrestricted use, distribution, and reproduction in any medium, provided the original author and source are credited. 